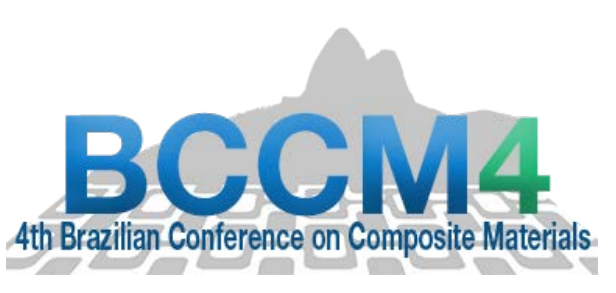

\title{
SIMULATION OF FLEXURAL STRESSES ON LAYERED NATURAL FIBRE/EPOXY COMPOSITE BEAMS
}

\author{
$\underline{\text { R.T. Durai Prabhakaran }}^{(1)}$, G.A. Ormondroyd ${ }^{(1,3)}$ and Guan Zhongwei (2) \\ (1) The BioComposites Centre, Bangor University, Gwynedd, UK \\ (2) School of Engineering, University of Liverpool, Liverpool, UK \\ (3) Department of Architecture and Civil Engineering, University of Bath, Bath, UK
}

https://doi.org/10.21452/bccm4.2018.16.05

\begin{abstract}
Biobased fibre reinforcements (hemp, jute, flax) derived from agricultural waste and forestry are increasing its potential towards advanced composites promoting environmental benefits and thermal recycling (including a reduction in CO2 emissions and the fossil fuel depletion). Currently, there is a growing interest of natural fibres due to its lower density, and higher modulus-to-density ratios compared to glass and carbon fibre reinforcements. The present work was intended to understand how the flax fibre layups and oreintation affect the behavior of laminated composites in bending. Unidirectional $\left[0^{0}\right]_{2 S}$, cross-ply $[0 / 90]_{S}$, and angle-ply [+45/-45 $]_{S}$ laminates made up of flax fibre reinforced epoxy composites are considered to study flexural stresses and mid-span deflections. Basic principles of the classical beam theory (CBT) are applied for obtaining analytical solutions, which were also compared with the finite element simulation results.
\end{abstract}

\section{Keywords}

Natural fibre, Epoxy, Flexural Loads, Cross/Angle-ply, Classical Beam Theory, FE analysis

\section{INTRODUCTION}

Recent state-of-the-art reviews on bio-based composites showed a rapid growth in research and innovation in the natural fibre composite area [1-4]. Polymer and fibres derived from fossil fuel resources are mostly non-biodegradable leading to a potential increased environmental burden. Scientists from academic and industries have shifted their focus toward bio-based materials, which are more eco-friendly (low environmental impact and low cost) and hence improving commercialization of biobased industrial products [5]. Fibres derived from agricultural waste/forestry as reinforcements have grown importance and their performance by implementing 
advanced chemistry and processing techniques. Henceforth bio-based composites are increasing their applications in replacing conventional composites by hybridization methods in aviation, wind, aerospace, defence and automotive areas [6].

Heterogeneous materials having two or more constituents (multi-phase) comprised of a matrix, fibre reinforcements (one or more fibres types), and nanoparticles require a thorough understanding to tailor the composite properties. Due to complex architecture, the materials have a large number of design variables. Selection of the right constituents, manufacturing methods and layups from endless combinations require modelling tools to design lightweight composites [7]. When designing such composites, the characteristics of layers should be known beforehand. FEM as an numerical method offers the possibility to quickly examine and evaluate laminate design at early stages of design long before a prototype is built.

From the literature review [8-12], it is clear to note that some experimental investigations were conducted to understand stresses in a layered flax/epoxy composite. Cerbu [10] studied mechanical behaviour of flax/epoxy and flax/glass/epoxy composites, where bidirectional flax woven fabrics are considered. Performance of bidirectional eight layered flax/epoxy composites showed higher mechanical properties in weft direction when compared to warp direction. Young's modulus in tensile (33.84\%)/bending (13.44\%) and normal tensile stress (40.63\%)/bending stress (12.69\%) is greater for weft direction compared to warp direction of the specimen. Similarly, Durai Prabhakaran et. al. [11-12] studied flexural performance of biaxial $\left( \pm 45^{\circ}\right)$ non-crimp glass and flax fabrics with super-sap epoxy resin. Symmetrical laminates with layered configuration are produced to demonstrate the effect of hybridization of flax/glass layups on bending properties. Limited research carried out to demonstrate the flexural performance comparison of flax/epoxy laminates with unidirectional, cross-ply, and angle-ply layups with symmetric configuration, as shown in Figure 1.

Theoretical and numerical analysis has been undertaken to determine stresses and mid-span deflections in layered composites in this study. Classical beam theory and finite element simulation have been used to examine the stress distribution in the symmetric laminates of flax/epoxy composites under flexural loading conditions. For the simulation of stresses, Solidworks ${ }^{\circledR}$ version 2018 software (Dassault Systems, UK) was used.

\section{SYMMETRIC LAMINATES AND LAYUPS}

In the present paper, laminates with varying fibre orientations are considered to understand how the fibre orientation and layup sequence in a symmetric configuration affects the performance of laminated composites in bending. The laminates are shown in Figure 1 , with $\left[0^{0}\right]_{2 \mathrm{~s}},[0 / 90]_{\mathrm{s}},[+45 /-$ 45]s having constituent properties i.e. flax fibre and epoxy resin are described in Table 1 . The four independent elastic properties for flax/epoxy lamina considered for analytical and simulation analysis are also given in Table 1. 

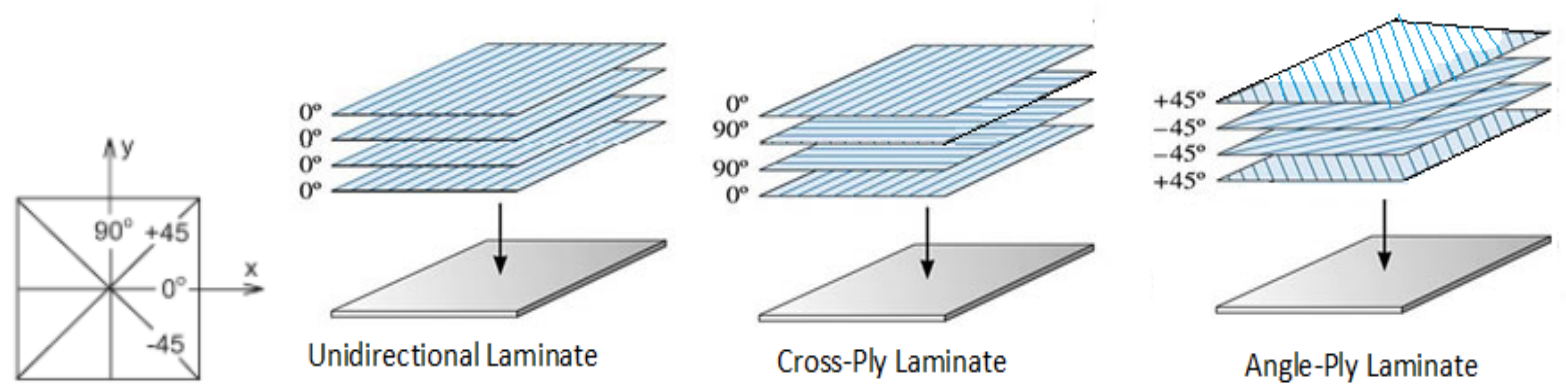

Figure 1: Symmetric laminates: layup’s with varying lamina fibre orientations

Table 1: Material properties of fibre, matrix and lamina [11-12]

\begin{tabular}{|c|c|c|c|c|c|c|}
\hline & \multicolumn{6}{|c|}{ Fibre - Flax fibre } \\
\hline Symbol & $(\%)$ & $E_{1 f}(\mathrm{GPa})$ & $E_{2 f}(\mathrm{GPa})$ & $G_{f}(\mathrm{GPa})$ & $\vartheta_{f}$ & $\rho_{\mathrm{f}}\left(\mathrm{g} / \mathrm{cm}^{3}\right)$ \\
\hline Value & 0.275 & 39.0 & 5.44 & 3.46 & 0.11 & 1.516 \\
\hline \multicolumn{7}{|c|}{ Matrix - Epoxy resin } \\
\hline Symbol & $(\%)$ & (GPa) & 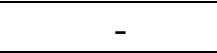 & $G_{m}(\mathrm{GPa})$ & $\vartheta_{m}$ & $\rho_{\mathrm{m}}\left(\mathrm{g} / \mathrm{cm}^{3}\right)$ \\
\hline Value & 0.725 & 3.70 & - & 1.37 & 0.35 & 1.152 \\
\hline \multicolumn{7}{|c|}{ Lamina - Flax/Epoxy single ply } \\
\hline Symbol & - & $\begin{array}{ll}E_{1} & (\mathrm{GPa})\end{array}$ & $E_{2}(\mathrm{GPa})$ & $G_{12}(\mathrm{GPa})$ & $\vartheta_{12}$ & $\rho_{c}\left(g / \mathrm{cm}^{3}\right)$ \\
\hline Value & - & 13.4 & 4.45 & 1.74 & 0.284 & 1.2794 \\
\hline
\end{tabular}

\section{THEORETICAL APPROACH}

In many applications, deflection of a beam plays a key role in the structure. This can happen when the beam is subjected to either static or dynamic loading conditions. It can cause durability concerns and hence, deflection and stress analysis for composite beams need to be thoroughly understood. In the present study, composite beams with dimensions of $80 \mathrm{~mm} \times 15 \mathrm{~mm} \times 4 \mathrm{~mm}$ are considered for three point bending analysis. Loading and supporting conditions as described in standards ISO 14125: 1998 are shown in Figure 2 used for the beam theory and finite element simulations.

According to the classical beam theory (CBT), the beam made of several layers of either same or different materials are placed either symmetrically or non-symmetrically to the median surface. In the current study symmetric layers with the same thickness and same material are considered to define a composite laminate (Figure 2). Laminates $\left[0^{0}\right]_{2 S},[0 / 90]_{S},[+45 /-45]_{s}$ are defined as symmetric transversely orthotropic laminated conditions. The stresses in a laminate vary from layer to layer, as well strains vary linearly across the beam thickness in spite of having laminae with different directional properties [7]. 


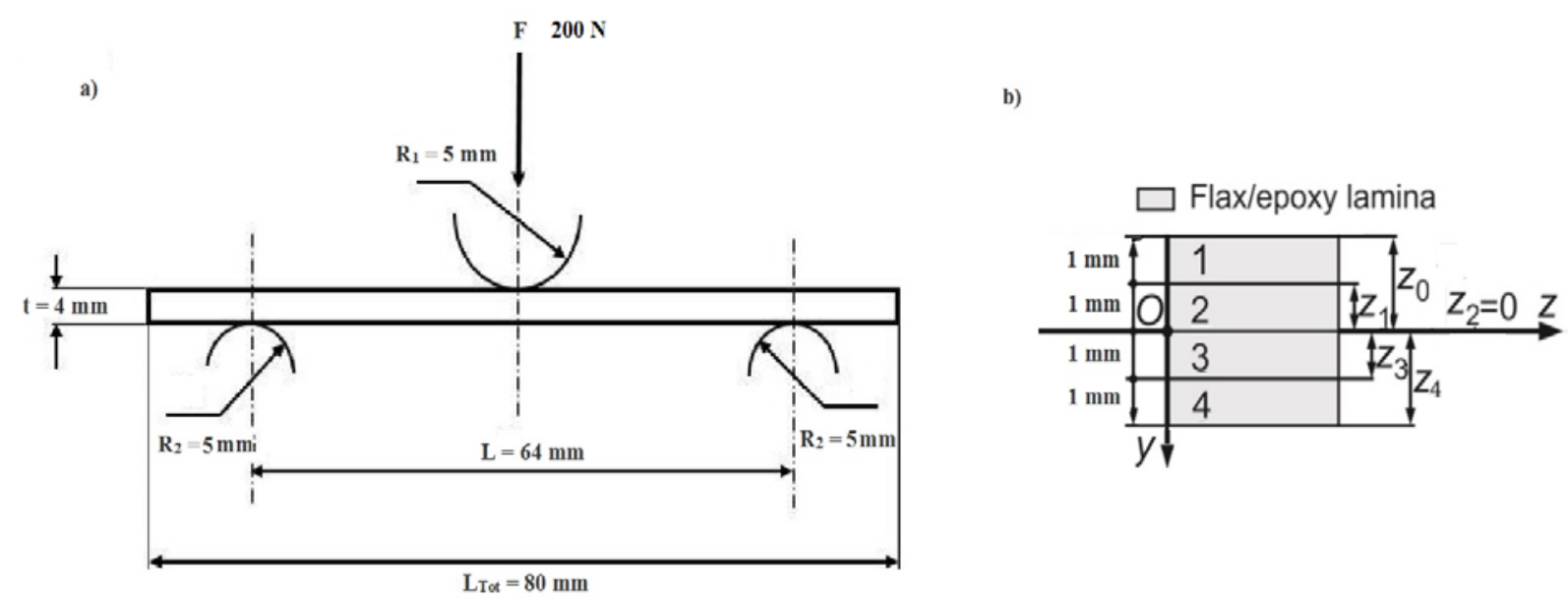

Figure 2: a) Load configuration of 3 point bending b) Thickness and coordinates of the lamina

From Table 1, using the constituent properties of fibre and matrix, stiffness matrix for a lamina can be defined as:

Stiffness Matrix [S] $=\left[\begin{array}{ccc}Q_{11} & Q_{12} & 0 \\ Q_{21} & Q_{22} & 0 \\ 0 & 0 & Q_{66}\end{array}\right]$

where $Q_{11}=\frac{E_{L}}{1-\vartheta_{L T} \vartheta_{T L}} ; \quad Q_{22}=\frac{E_{T}}{1-\vartheta_{L T} \vartheta_{T L}} ; \quad Q_{12}=\frac{\vartheta_{T L} E_{L}}{1-\vartheta_{L T} \vartheta_{T L}} ; Q_{66}=G_{L T}$;

$\vartheta_{L T} E_{T}=\vartheta_{T L} E_{L}$

According to beam theory [7], total plate constitutive equation of a multi-layered laminate is used to calculate force and moment resultants

$\left[\begin{array}{l}N \\ M\end{array}\right]=\left[\begin{array}{ll}A & B \\ B & D\end{array}\right]\left[\begin{array}{l}\varepsilon_{0} \\ k\end{array}\right]$

where strains and plate curvatures are estimated by using

$\varepsilon_{0}=\frac{\partial u_{0}}{\partial x} \quad k=-\frac{\partial^{2} w}{\partial x^{2}}$

The elements of matrix [A], [B], and [D] are defined by equation (6), as shown below :

$A_{i j}=\sum_{k=1}^{n}\left(\bar{Q}_{i j}\right)_{k}\left(h_{k}-h_{k-1}\right) \quad B_{i j}=\frac{1}{2} \sum_{k=1}^{n}\left(\bar{Q}_{i j}\right)_{k}\left(h_{k}^{2}-h_{k-1}^{2}\right)$
$D_{i j}=\frac{1}{3} \sum_{k=1}^{n}\left(\bar{Q}_{i j}\right)_{k}\left(h_{k}^{3}-h_{k-1}^{3}\right)$

Using equation (4) and equation (6), stress-strain relation for an orthotropic lamina referred to arbitrary axes can be determined by using equation (7)

$\left\{\begin{array}{c}k_{x}^{0} \\ k_{y}^{0} \\ k_{x y}^{0}\end{array}\right\}=\left[\begin{array}{lll}\delta_{11} & \delta_{12} & \delta_{16} \\ \delta_{21} & \delta_{22} & \delta_{26} \\ \delta_{61} & \delta_{62} & \delta_{66}\end{array}\right]\left\{\begin{array}{c}M_{x} \\ M_{y} \\ M_{x y}\end{array}\right\}$

Considering the beam section shown in Figure 2, assuming beam subjected to 3-point bending, the differential equation of deformed section of beam is derived from the classical beam theory as $\frac{d^{2} w_{0}}{d x^{2}}=-\frac{M}{E_{x} I}$

Applying simply supported beam boundary conditions and solving the above equation leads to the following [7]:

$E_{x}=\frac{12}{h^{3} \delta_{11}}$ 


$$
\begin{aligned}
& w_{0}=-\frac{F l^{2}}{48 E_{x} I} x\left[3-\left(\frac{2 x}{l}\right)^{2}\right] \quad w_{0 \text { max }}=\frac{F l^{3}}{48 E_{x} I} \\
& \left(\sigma_{\max }^{f}\right)=\frac{3 F_{\max } l}{2 b h^{2}}\left(1+6\left(\frac{w_{\max }}{l}\right)^{2}-3\left(\frac{w_{\max } h}{l^{2}}\right)\right)
\end{aligned}
$$

[A], [B], [D] matrices for the four layered symmetric laminates $\left[0^{0}\right]_{2 S},[0 / 90]_{S},[+45 /-45]_{S}$ can be estimated from the lamina (or each ply) transformed stiffness matrix elements as given in Table 2. Stresses in each lamina and the mid-span deflections of the composite beam are estimated for flax/epoxy symmetric laminates are given in Table 3 and Table 4.

\begin{tabular}{|c|c|c|c|c|c|c|c|}
\hline \multirow{2}{*}{\multicolumn{2}{|c|}{$\begin{array}{l}\text { Lamina number and } \\
\text { fibre angle } \theta\end{array}$}} & $\bar{Q}_{11}$ & $\bar{Q}_{22}$ & $\bar{Q}_{12}$ & $\bar{Q}_{66}$ & $\bar{Q}_{16}$ & $\bar{Q}_{26}$ \\
\hline & & \multicolumn{6}{|c|}{$\mathrm{MPa}$} \\
\hline \multicolumn{8}{|c|}{ Unidirectional Laminates $\left[0^{0}\right]_{2 S}$} \\
\hline $1^{\text {st }}, 2^{\text {nd }}, 3^{\text {rd }}, 4^{\text {th }} \mathrm{Ply}$ & $0^{0}$ & 13769 & 4572 & 1298 & 1740 & 0 & 0 \\
\hline \multicolumn{8}{|c|}{ Cross-Ply Laminate $[0 / 90]_{\mathrm{S}}$} \\
\hline $1^{\text {st }} \mathrm{Ply}, 4^{\text {th }} \mathrm{Ply}$ & $0^{0}$ & 13769 & 4572 & 1298 & 1740 & 0 & 0 \\
\hline $2^{\text {nd }}$ Ply, $3^{\text {rd }}$ Ply & $90^{0}$ & 4572 & 13769 & 1298 & 1740 & 0 & 0 \\
\hline \multicolumn{8}{|c|}{ Angle-Ply Laminate $[+45 /-45]_{\mathrm{S}}$} \\
\hline $1^{\text {st }} \mathrm{Ply}, 4^{\text {th }} \mathrm{Ply}$ & $+45^{0}$ & 6975 & 6975 & 3495 & 3936 & 2299 & 2299 \\
\hline $2^{\text {nd }}$ Ply, $3^{\text {rd }}$ Ply & $-45^{0}$ & 6975 & 6975 & 3495 & 3936 & -2299 & -2299 \\
\hline
\end{tabular}

Table 2: Transformed Stiffness Matrix of Laminates with 0, 90, 45, -45 orientations
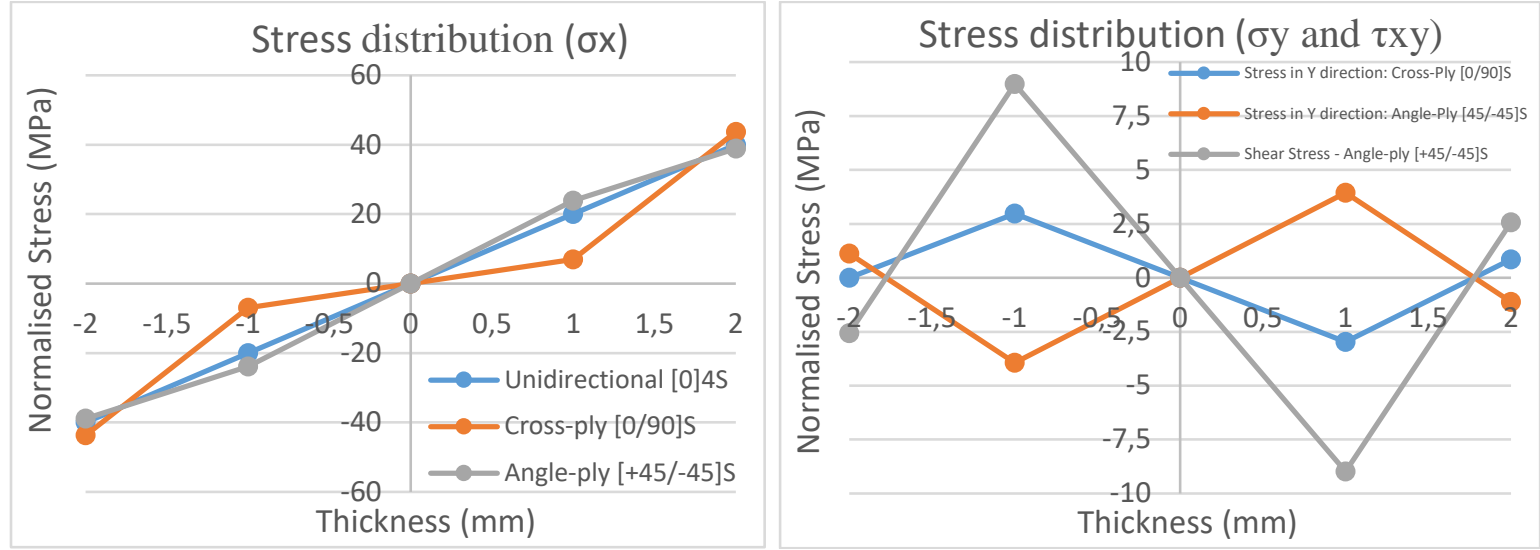

Figure 3: The axial and shear stress variations along the thickness of flax/epoxy laminate 
Table 3: Stress distribution along the thickness of the laminate subjected to 3 point bending

\begin{tabular}{|l|c|c|c|c|}
\hline $\begin{array}{l}\text { Lamina } \\
\text { No }\end{array}$ & $\begin{array}{c}\text { Angle/fibre } \\
\text { orientation }\end{array}$ & $\begin{array}{c}\text { Stress }\left(\sigma_{\mathrm{x}}\right) \\
\mathrm{MPa}\end{array}$ & $\begin{array}{c}\text { Stress }\left(\sigma_{\mathrm{y}}\right) \\
\mathrm{MPa}\end{array}$ & $\begin{array}{c}\text { Shear Stress }\left(\tau_{\mathrm{xy}}\right) \\
\mathrm{MPa}\end{array}$ \\
\hline \multicolumn{5}{|c|}{ Unidirectional Laminates $\left[0^{0}\right]_{2 \mathrm{~S}}$} \\
\hline Ply \#1 & $0^{0}$ & -40 & 0 & 0 \\
\hline Ply \#2 & $0^{0}$ & -20 & 0 & 0 \\
\hline Ply \#3 & $0^{0}$ & 20 & 0 & 0 \\
\hline Ply \#4 & $0^{0}$ & 40 & 0 & 0 \\
\hline \multicolumn{5}{|c|}{ Cross-Ply Laminate [0/90]s } \\
\hline Ply \#1 & $0^{0}$ & -43.7 & -0.85 & 0 \\
\hline Ply \#2 & $90^{0}$ & -6.94 & 2.97 & 0 \\
\hline Ply \#3 & $90^{0}$ & 6.94 & -2.97 & 0 \\
\hline Ply \#4 & $0^{0}$ & 43.7 & 0.85 & 0 \\
\hline \multicolumn{5}{|c|}{ Angle-Ply Laminate [+45/-45]s } \\
\hline Ply \#1 & $+45^{0}$ & -38.9 & 1.12 & -2.57 \\
\hline Ply \#2 & $-45^{0}$ & -23.9 & -3.94 & 8.98 \\
\hline Ply \#3 & $-45^{0}$ & 23.9 & 3.94 & -8.98 \\
\hline Ply \#4 & $+45^{0}$ & 38.9 & -1.12 & 2.57 \\
\hline
\end{tabular}

\section{NUMERICAL SIMULATION}

Finite element models were developed using SOLIDWORKS ${ }^{\circledR}$ version 2018 (Dassault Systems, UK) to help understand flexural behaviour (analysis of stresses, strains and displacements) of a symmetric laminate in bending. To simulate the real material behaviour it was necessary to define density and mechanical properties of the material in solidworks as given in Table 1. For any simulation, geometry, material, and boundary conditions are defined. The flax/epoxy specimens considered in the study have symmetry and therefore, unidirectional and cross-ply will have symmetry in the ply sequence, material, and geometrical symmetry, whereas the angle-ply has no through thickness plane of symmetry for material orientation.

To simulate 3 point bending with the "simply supported" assumption, the load and deflection follows linear relationship. In the current study, comparison of three symmetric laminates are analysed for bending assuming load applied at centre of beam as $200 \mathrm{~N}$. The sum of reaction forces acting at supports are equal to $200 \mathrm{~N}$ in reverse direction to load applied. Specimen geometry is $80 \times 15 \times 4 \mathrm{~mm}^{3}$, where span (L) were set as $64 \mathrm{~mm}$ as shown in Figure 2. SolidWorks used the directions $\mathrm{X}, \mathrm{Y}$, and $\mathrm{Z}$ of the global Cartesian system of coordinates having mixed mesh with high quality having total nodes 23208, and elements 14628. 


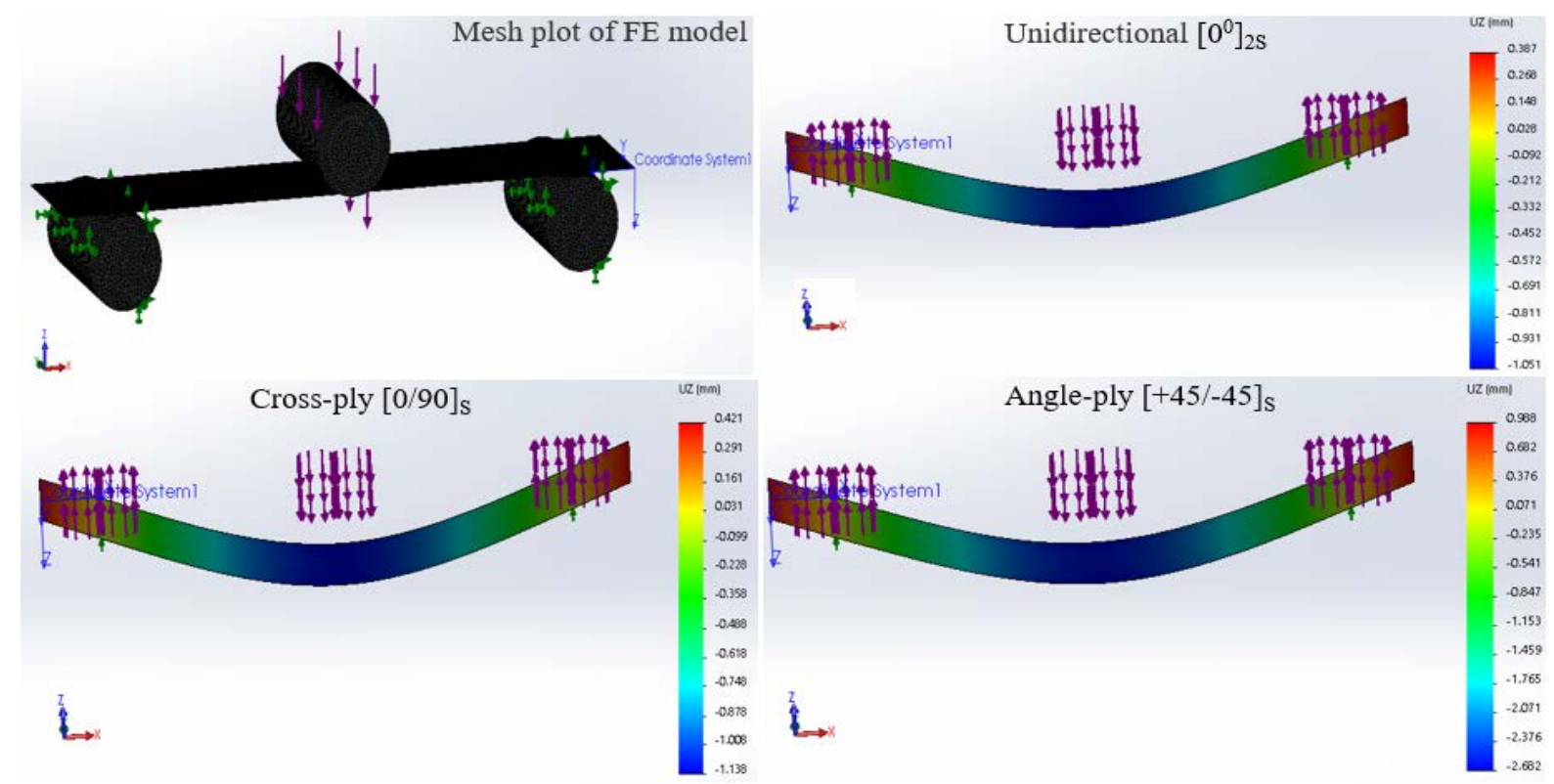

Figure 4: Finite Element Model and Mid-span Deflection of Symmetric Flax/Epoxy Laminate

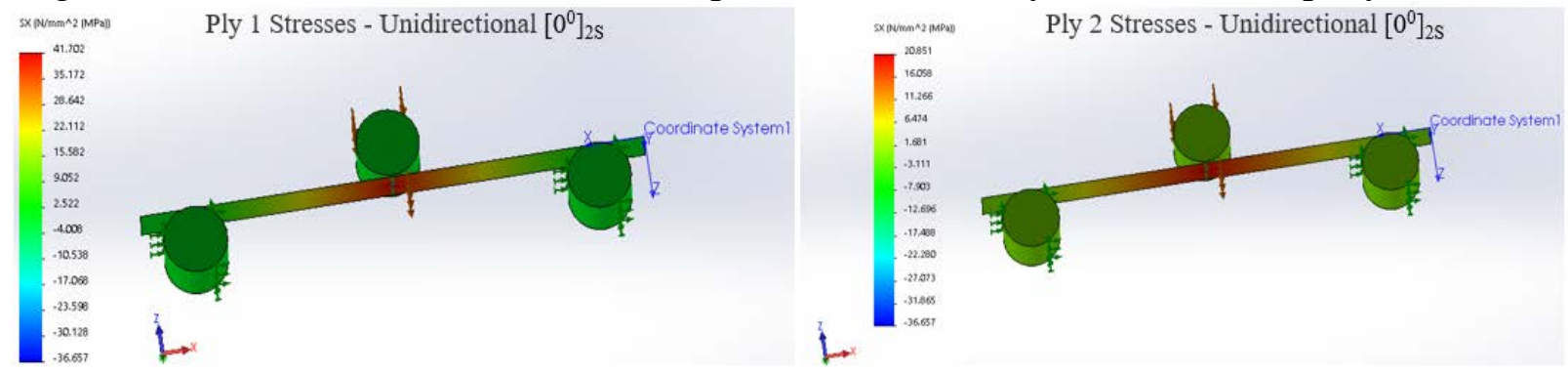

Figure 5: Ply Stresses for Unidirectional [0] $]_{2 s}$ Flax/Epoxy Composite

\section{RESULTS AND DISCUSSIONS}

The symmetry or asymmetry of a laminate based on angle, material, and thickness of plies, may cancel out some elements of the extensional stiffness [A], coupling stifness [B], and bending stiffness [D] matrices. In the current work, laminates $\left[0^{0}\right]_{2 \mathrm{~S}},[0 / 90]_{\mathrm{S}},[+45 /-45]_{\mathrm{S}}$ are considered as symmetry therefore elements of [B] matrix is zero and elements of Q matrix for unidirectional and cross-ply i.e. $\left[\mathrm{Q}_{16}\right]$ and $\left[\mathrm{Q}_{26}\right]$ are zero. According to $\mathrm{CBT}$, symmetric laminates subjected to forces only have zero midplane curvatures reducing or zeroing out the coupling of forces and bending moments, normal and shear forces, or bending and twisting moments. Laminates having angle/symmetry, and number of plies the same but change the stacking sequence influences the interlaminar stresses.

For the current study, three point bending configuration has been adopted to study flax/epoxy laminates. To compare the laminate performance under load $\mathrm{F}(200 \mathrm{~N})$ is applied at centre of beam, which is subjected to resultant moment $M_{x}(213.3 \mathrm{~N} . \mathrm{m} / \mathrm{m}), M_{y}, M_{x y}$ equal to zero. As no other forces acting on beam, resultant forces $\mathrm{N}_{\mathrm{x}}, \mathrm{N}_{\mathrm{y}}, \mathrm{N}_{\mathrm{xy}}$ are defined as zero, whereas the fibre direction coincides with the global axis for unidirectional and cross-ply laminates. Table 3 lists the individual ply stresses when a load is acting at centre of beam. For unidirectional and cross-ply, shear stress and midplane strains are zero because there are no in-plane forces acting and the laminate is symmetric. The state of stress through the thickness of the laminate (due to bending) results into laminate stiffness (estimated using eqn. (9). Figure 3 demonstrates the normal stress 
and shear stress variations across the thickness of laminates. Similarly, strain distribution through thickness of laminate is linear and plies used as outer contribute more to stiffness than inner layers of the laminate. Therefore bending stiffness for unidirectional is higher than cross-ply and angleply as given in Table 4 . From the analytical results, it has been shown that shear stress $\left(\tau_{\mathrm{xy}}\right)$ in angle-ply is higher than the normal stress $\left(\sigma_{y}\right)$, and this leads to laminate twisting under bending loads. Shear stress for the unidirectional and cross-ply laminate are computed as zero, resulting no twisting.

Using SolidWorks, the distribution of the normal stress $\left(\sigma_{x}=S_{11}\right)$ across the thickness of the unidirectional laminate (ply 1 and ply 2) are shown in Figure 5. The stress values shown in the plots are in the first and fourth ply as $41.7 \mathrm{MPa}$ and in the second and third ply as $20.8 \mathrm{MPa}$, nearly matches with the analytical (CBT) solution computed for each lamina, refer Table 3 . The distribution of vertical displacement (mid-span deflection) of the laminate $W_{0 \max }$ in the direction of the Z-axis are plotted in all three cases of laminate, as shown in Figure 4 and Table 4 . The deflection obtained for the load (200 N) applied at centre of beam demonstrates unidirectional and cross-ply have better performance compared to angle-ply (deflection higher than $[0]_{2 s}$ and $\left.[0 / 90]_{s}\right)$.

Table 4: Bending Properties of Unidirectional, Cross-ply, \& Angle-ply Flax/Epoxy Laminates

\begin{tabular}{|l|c|c|c|c|}
\hline $\begin{array}{l}\text { Composite } \\
\text { Plate Type }\end{array}$ & $\begin{array}{c}\text { Bending } \\
\text { Modulus } \\
\mathrm{E}_{\mathrm{x}}\end{array}$ & $\begin{array}{c}\text { Bending } \\
\text { Stress } \\
\sigma_{f b}\end{array}$ & \multicolumn{2}{|c|}{$\begin{array}{c}\text { Mid-Span Deflection } \\
W_{\text {max }}\end{array}$} \\
\cline { 2 - 5 } & $\begin{array}{c}\text { Theoretical } \\
(\mathrm{GPa})\end{array}$ & $\begin{array}{c}\text { Theoretical } \\
(\mathrm{MPa})\end{array}$ & $\begin{array}{c}\text { Theoretical } \\
(\mathrm{mm})\end{array}$ & $\begin{array}{c}\text { Numerical } \\
(\mathrm{mm})\end{array}$ \\
\hline Unidirectional $[0]_{2 \mathrm{~S}}$ & 13.4 & 77.9 & 1.02 & 1.05 \\
\hline Cross Ply [0/90] & 12.3 & 78.0 & 1.11 & 1.13 \\
\hline Angle Ply [+45/-45] & 5.01 & 84.2 & 2.72 & 2.68 \\
\hline
\end{tabular}

\section{CONCLUSIONS}

The work reports results obtained in numerical modelling of flexural behaviour (in bending) of flax/epoxy composites with symmetrical layups (unidirectional, cross-ply, and angle-ply) and these results are validated analytically using the classical beam theory. Based on the work, some conclusions may be drawn as follows :

- Flexural stiffness for the unidirectional laminates is greater than cross-ply and angle-ply flax/epoxy laminates.

- From the results, it has been shown that shear stress $\left(\tau_{x y}\right)$ in angle-ply is higher than the stress $\left(\sigma_{\mathrm{y}}\right)$, and this leads to laminate twisting under bending loads.

- The laminate (angle-ply) presents much higher mid-span deflection than symmetric unidirectional and cross-ply flax/epoxy laminates.

Future experiments are planned to study bending properties for the three symmetrical layups of flax/epoxy composites and evaluate theoretical/numerical results presented in the article.

\section{ACKNOWLEDGEMENTS}

The authors of the paper would like to acknowledge the financial support provided by the Welsh Government and Higher Education Funding Council for Wales through the Sêr Cymru National Research Network for Low Carbon, Energy and Environment. 
$4^{\text {th }}$ Brazilian Conference on Composite Materials. Rio de Janeiro, July $22^{\text {nd }}-25^{\text {th }}, 2018$

\section{REFERENCES}

[1] Pickering, K., 'Properties and performance of natural -fibre composites', $1^{\text {st }}$ Edition (Woodhead Publishing, Cambridge, 2008).

[2] Edgars, S., 'Mechanical Properties of flax fibers and their composites', Licentiate thesis (Luleå University of Technology, Sweden, 2006).

[3] Aslan, M., Sørensen, B.F. and Madsen, B. 'Characterization of flax fibres \& flax fibre composites: Bending cellulose based sources of materials', PhD Thesis (DTU Wind Energy, Denmark, 2012).

[4] Pickering, K.L., Aruan Efendy, M.G., Le, T.M., 'A review of recent developments in natural fibre composites and their mechanical performance', Composites: Part A, 83 (2016) 98-112.

[5] Yan, L., Chouw, N. and Jayaraman, K., 'Flax fibre and its composites - A Review', Composites Part B: Engineering, 56 (2014) 296 - 317.

[6] Durai Prabhakaran, R.T., 'A critical review on future materials for wind turbine blades', International Journal of Materials Engineering Innovation, 5 (2) (2014) 81-99.

[7] Agarwal, B.D., Broutman, L.J. and Chandrashekhara, K., 'Analysis and performance of fiber composites', $3^{\text {rd }}$ Edition (John Wiley \& Sons, Inc., New Delhi, 2006).

[8] Meng, M., Le, H.R., Rizvi, M.J. and Grove, S.M., '3D FEA modelling of laminated composites in bending and their failure mechanisms', Composite Structures, 119 (2015) 693 - 708.

[9] George, J., Ivens, J. and Verpoest, I., 'Mechanical properties of flax fibre reinforced epoxy composites', Die Angewandte Makromolekulare Chemie, 272 (1999) 41-45.

[10]Cerbu, C., 'Practical solution for improving the mechanical behaviour of the composite materials reinforced with flax woven fabric', Advances in Mechanical Engineering, 7 (2) (2015) 01 - 11.

[11]Durai Prabhakaran, R.T., Madsen, Bo., Toftegaard, H. and Markussen, C.M., 'Flexural Properties of Hybrid Natural Composite: Micromechanics and Experimental Assessment', Proceedings of an International Conference, New Delhi, December, 2012 (ACMFMS, IIT Delhi, 2012) 469 - 472.

[12]Durai Prabhakaran, R.T., Toftegaard, H., Markussen, C.M. and Madsen, Bo., 'Experimental and Theoretical Assessment of Flexural Properties of Hybrid Natural Fibre Composites', Acta Mechanica., 225 (10) (2014) 2775 - 2782. 